Review Article

\title{
Cynanchum paniculatum and Its Major Active Constituents for Inflammatory-Related Diseases: A Review of Traditional Use, Multiple Pathway Modulations, and Clinical Applications
}

\author{
Jing-xian Chen, ${ }^{1,2}$ Chien-shan Cheng, ${ }^{3,4}$ Jie Chen, ${ }^{5}$ Ling-ling Lv, ${ }^{1}$ Zi-jie Chen, ${ }^{6}$ \\ Chuan Chen $\mathbb{D}^{7}{ }^{7}$ and Lan Zheng $\mathbb{D}^{1,2}$ \\ ${ }^{1}$ Department of Traditional Chinese Medicine, Shanghai Jiao Tong University School of Medicine Affiliated Ruijin Hospital, \\ Shanghai 200025, China \\ ${ }^{2}$ Workstation of Xia Xiang, National Master of Traditional Chinese Medicine, Department of Traditional Chinese Medicine, \\ Ruijin Hospital, School of Medicine, Shanghai Jiao Tong University, Shanghai 200025, China \\ ${ }^{3}$ Department of Integrative Oncology, Fudan University Shanghai Cancer Center, Shanghai 200032, China \\ ${ }^{4}$ Department of Oncology, Shanghai Medical College, Fudan University, Shanghai 200032, China \\ ${ }^{5}$ Department of Orthopedics, Shanghai Institute of Traumatology and Orthopedics, Ruijin Hospital, \\ Shanghai Jiao Tong University School of Medicine, Shanghai 200025, China \\ ${ }^{6}$ Shanghai Yangpu Hospital of Traditional Chinese Medicine, Shanghai 200090, China \\ ${ }^{7}$ Shanghai Geriatrics Institute of Chinese Medicine, Shanghai University of Traditional Chinese Medicine, \\ Shanghai 200031, China
}

Correspondence should be addressed to Chuan Chen; ch9453@126.com and Lan Zheng; windy9453@126.com

Received 23 April 2020; Accepted 27 May 2020; Published 23 July 2020

Guest Editor: Yuan Xu

Copyright ( $\odot 2020$ Jing-xian Chen et al. This is an open access article distributed under the Creative Commons Attribution License, which permits unrestricted use, distribution, and reproduction in any medium, provided the original work is properly cited.

Cynanchum paniculatum Radix, known as Xuchangqing in Chinese, is commonly prescribed in Chinese Medicine (CM) for the treatment of various inflammatory diseases. The anti-inflammatory property of Cynanchum paniculatum can be traced from its wind-damp removing, collaterals' obstruction relieving, and toxins counteracting effects as folk medicine in CM. This paper systematically reviewed the research advancement of the pharmacological effects of Cynanchum paniculatum among a variety of human diseases, including diseases of the respiratory, circulatory, digestive, urogenital, hematopoietic, endocrine and metabolomic, neurological, skeletal, and rheumatological systems and malignant diseases. This review aims to link the long history of clinical applications of Cynanchum paniculatum in CM with recent biomedical investigations. The major bioactive chemical compositions of Cynanchum paniculatum and their associated action mechanism unveiled by biomedical investigations as well as the present clinical applications and future perspectives are discussed. The major focuses of this review are on the diverse mechanisms of Cynanchum paniculatum and the role of its active components in inflammatory diseases.

\section{Introduction}

Cynanchum paniculatum (Xuchangqing in Chinese, Figures 1(a)) has been used as folk medicine by Chinese medicine $(\mathrm{CM})$ practitioners for more than two thousand years to treat various inflammatory diseases. The earliest record of Cynanchum paniculatum traced back to Shennong's Materia Medica Classic, which is the oldest Chinese pharmacopeia compiled in the Han Dynasty about 100
Anno Domini (AD). Xuchangqing is recognized as one of the top-grade drugs (tonic and nontoxic) and has a long history of clinical applications for treating infectious diseases [1]. As a folk medicine, the roots of Cynanchum paniculatum can be applied orally in the form of water extract either alone or in decoction. In CM theory, the main effects of Xuchangqing include dispelling wind, relieving pain, promoting blood circulation, detoxification, and reducing swelling [2, 3]. Xuchangqing is recognized in treating rheumatic arthralgia, 


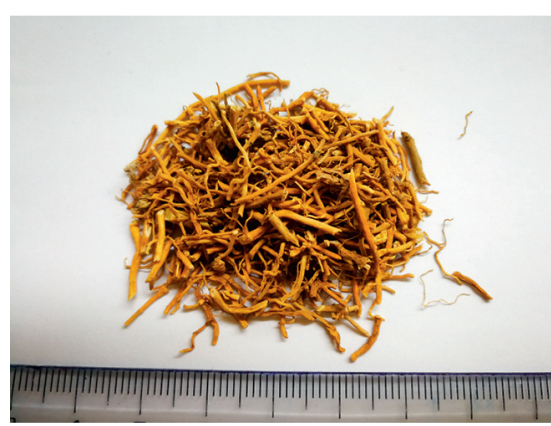

(a)

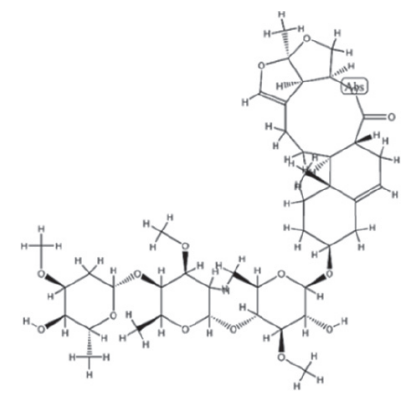

(d)<smiles>COc1ccc(C(C)=O)c(O)c1</smiles>

(b)

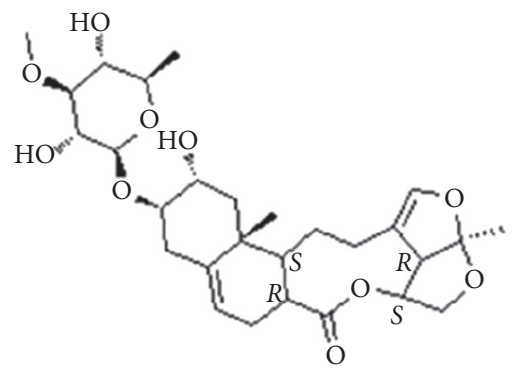

(e)<smiles>COc1ccc2c3c(c4cc(OC)c(OC)cc4c2c1)C[C@@H]1CCCCN1C3</smiles>

(c)<smiles>COc1ccc(C(C)=O)cc1O</smiles>

FIGURE 1: Dry herb of Cynanchum paniculatum and chemical composition of its major constituent: (a) dry herb of XCQ; (b) paeonol (C99H10O3, CAS number 552-41-0); (c) antofine (C23H25NO3, CAS number 32671-82-2); (d) cynanversicoside A (C42H64O15, CAS number 138875-31-7); (e) cynanversicoside C (C28H40O10, CAS number 934701-03-8); (f) 3-hydroxy-4-methoxy-acetophenone (C9H10O3, CAS number 6100-74-9).

odontalgia, dysentery, diarrhea, malaria, abdominal pain, chest pain, eczema, and urticaria. The use of Xuchangqing in managing these symptoms is linked to the traditional concept of treating wind-damp syndrome $[2,3]$.

Modern pharmacological studies show that the chemical composition of Cynanchum paniculatum majorly includes phenolic compounds [2,3]. In recent years, the development of separation and detection techniques, such as liquid chromatography-mass spectrometry, facilitated the phytochemical studies on Cynanchum paniculatum. Researchers identified many secondary metabolites from Cynanchum paniculatum, including phenol derivatives, polysaccharides, glycosides, and alkaloids [4-7]. Pharmacological research shows that the chemical composition or extract of Cynanchum paniculatum has analgesic, sedative, anti-inflammatory, antibacterial, antiallergic, and anticancer effects [3, 8-10]. Cynanchum paniculatum is widely used for treating gastroenterological, oncological, dermatological, and orthopedics diseases in CM practices.

In the last decade, increasing research has focused on the Cynanchum paniculatum and its active components in the treatment of inflammatory diseases (Figure 2); however, a systematic review was not yet available. In this review, the advances in the traditional application, phytochemistry, pharmacology, and the current research progress of Cynanchum paniculatum on treating various diseases are systematically reviewed. Moreover, we focused on elaborating the potential molecular mechanism of the combination of Cynanchum paniculatum and other herbs, in vivo research, and clinical applications. The most relevant studies were published in English and Chinese. Electronic databases were extensively searched from their literature research through March 2020, using the following databases: US National Library of Medicine MEDLINE database (via PubMed), Allied and Complementary Medicine Database (AMED), Cumulative Index to Nursing and Allied Health Literature (CINAHL), and China Journals Full Text Database (via China National Knowledge Infrastructure, CNKI). The terms and keywords for searching included Xuchangqing, Cynanchum paniculatum, anti-inflammation, studies mechanism, pharmacology, toxicology, and in vivo. Further manual searches of our own documentation and cross-referencing of identified articles were conducted. After systematic review, we did not identify any previous review article regarding the anti-inflammatory effect, the application in inflammatory diseases, and safety Cynanchum paniculatum until the completion of this paper.

\section{Traditional Usages of Cynanchum paniculatum in Chinese Medicine}

In view of its wide range of pharmacological activities, Cynanchum paniculatum has long been used as a medicinal plant in China. Ever since the first documentation of Xuchangqing as a top-grade medicine in Shennong Materia Medica, Cynanchum paniculatum was frequently cited in many other medical literatures, such as the Supplement to Recipes Worth A Thousand Gold (Qianjin Yi Fang, Tang 


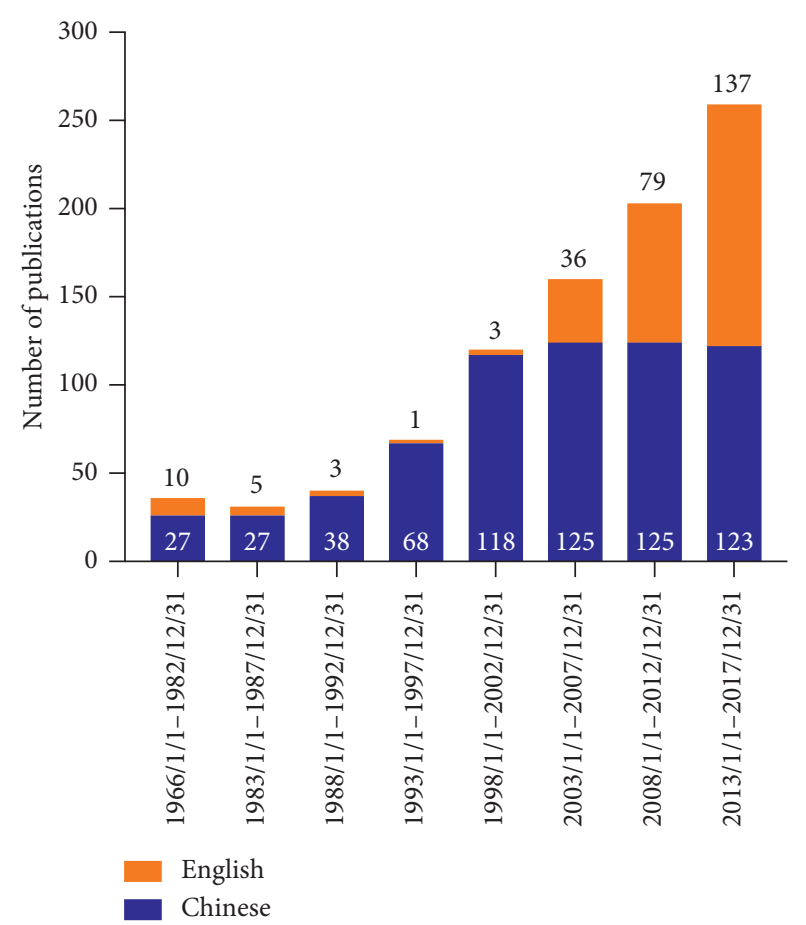

FIgURE 2: The number of publications by year showed an increase of research attention on Cynanchum paniculatum and its major constituents in recent years across the Chinese and English literature.

Dynasty, AD 682), Taiping Holy Prescriptions for Universal Relief (Tai Ping Sheng Hui Fang, Song Dynasty, AD 992), and Compendium of Materia Medica (Ben Cao Gang $\mathrm{Mu}$, Ming Dynasty, AD 1590) for the treatment of wind-damp syndrome, similar to other acute infectious diseases such as tuberculosis, acquired immune deficiency syndrome (AIDS), malaria, fevers, acute urinary infection, and abscesses $[11,12]$. However, there is a potential confusion on the source of Xuchangqing across ancient literature among Dysosma versipellis, Dicliptera chinensis, Cynanchum atratum, Cynanchum stauntonii, etc. $[11,13]$. The reason for this confusion may be due to the use of Cynanchum paniculatum radix for medicinal purposes; the whole plant was not recorded in detail by ancient herbology literature $[11,13-15]$.

As a single herbal medication, Xuchangqing was documented in Shennong Materia Medica for the treatment of treating hallucination and mental disorder, parasitic and virus, phytophthora, and malaria [1]. It was recorded to promote health and general well-beings with long-term use [1]. In Simple Herbs (Jian Yi Cao Yao, Qing Dynasty, AD 1822), Xuchangqing was recorded to treat soft tissue injuries and pain [16], while in Medical Characteristics of Raw Herb (Sheng Cao Yao Xing Bei Yao, Qing Dynasty, AD 1872), Xuchangqing containing medicinal liquor was used for the treatment of rheumatoid arthritis [16]. As a component in prescriptions, contemporarily, Xuchangqing is recorded in Yangzheng Xiaoji capsules and Yunxiang Qufeng analgesic spray (Yun Xiang Qu Feng Zhi Tong Ting) in the 2015 edition
Chinese Pharmacopoeia for the clinical application as adjuvant therapy for malignant diseases, aches, and pains of muscles and joints, respectively $[17,18]$.

Regarding the clinical application of Xuchangqing in daily $\mathrm{CM}$ clinics, our research group inherits the experience from a National Master of Traditional Chinese Medicine, Professor Xia Xiang, in our long-term clinical practice [19]. According to the recommended dosage by the pharmacoencyclopedia of Chinese medicinal herbs [20], Xuchangqing is commonly used at a conventional dose of $15 \mathrm{~g}-30 \mathrm{~g}$ per time into herbal decoctions. As a single herb, Xuchangqing water decoction at a dosage of $15 \mathrm{~g}$ per adult per day is commonly used to manage symptoms, such as nasal congestion caused by chronic rhinopharyngitis, runny nose and itching dry cough caused by chronic cough, eczema caused by allergic dermatitis, abdominal pain, and diarrhea caused by chronic enteritis in aims to regulate immune and inflammatory reactions. A dosage of $30 \mathrm{~g}$ per adult per day is commonly used to manage chronic joint pain and repeated tissue edema, such as rubella itching. As in drug pairs, the combination of Xuchangqing with Jixuecao (Centella asiatica) at 1:1 ratio is routinely used in clinical practices for management of liver fibrosis, interstitial lung disease, intestinal adhesion, and other fibrous hyperplasia caused by chronic inflammation. The combination of Xuchangqing with Huangqi (Astragali Radix) at $1: 1$ to $1: 4$ ratio is used to promote tissue repair for the treatment of recurrent oral ulcers, gastric erosion ulcers, vascular endothelial cell damage, etc. Furthermore, the combination of Xuchangqing with Tufuling (Smilacis Glabrae Rhizoma) at 1:1 ratio is used for the treatment of rheumatic arthritis, muscle diseases, and degenerative diseases of bone and joints. Together, the clinical application of Xuchangqing is closely related to its traditional $\mathrm{CM}$ effects of removing wind and pain, promoting blood circulation, clearing heat, and relieving itching. In combination with modern pharmacological research and molecular biology, understanding of inflammatory diseases will promote the accurate application and improve overall treatment efficacy.

\section{Phytochemistry of Cynanchum paniculatum: A Focus on Phenolic Derivatives}

The chemical composition of Cynanchum paniculatum is similar to the other Asclepiadaceae plants, which consists mostly of phenolic derivatives [21, 22]. There is increasing research and continuous identification of novel components of Cynanchum paniculatum with the advances in technologies regarding extraction, isolation, and identification. Paeonol (C99H10O3, CAS Number 552-41-0, PubChem CID 11092, Figure 1(b)) is a phenolic compound accounts for around $1 \%$ of the entire dry Cynanchum paniculatum and is also a major active compound in Xuchangqing $[21,22]$. Other components, such as cynapanosides, phenanthroindolizidine alkaloid antofine $(\mathrm{C} 23 \mathrm{H} 25 \mathrm{NO} 3, \mathrm{CAS}$ Number 32671-82-2, PubChem CID 639288, Figure 1(c)), cynanversicoside A (C42H64O15, CAS Number 138875-317, Figure $1(\mathrm{~d})$ ) and cynanversicoside C (C28H40O10, CAS 
Number 934701-03-8, Figure 1(e)), and 3-hydroxy-4methoxy-acetophenone (C9H10O3, CAS Number 6100-749, PubChem CID 24885509, Figure 1(f)) were identified as early as the 1980s to 1990 s. Other components, such as neocynapanogenins and paniculatumosides, had also been identified [15, 21-23]. It is worth noting that in the recent five years, various new C21 steroidal glycosides have been discovered, such as paniculatumoside $G$ and neocynapanogenin C identified in 2017 [24] and paniculatumoside $\mathrm{H}$ and paniculatumoside I identified in 2019 [25]. However, most of the biological activity assessments of these newly identified components remain preliminary at in vitro levels.

\section{Anti-Inflammatory Pharmacological Studies of Cynanchum paniculatum}

Inflammation is a complex biological response to living tissue injury by harmful stimuli, such as viral infection, microbial infection, chemical irritants, and damaged cells. The process of inflammation involved various aspects, including the immune cells, molecular mediators, and blood vessels. Aside from acute infection, where a specific pathogen triggers adaptive immunity, inflammation may also involve a variety of diseases, such as periodontitis, arthritis, asthma, gastrointestinal disorders, and even cancer. Several molecular mediators and pathways are closely connected with inflammatory responses, such as inflammatory cytokines tumor necrosis factor-alpha (TNF- $\alpha$ ), interleukins (ILs), and cyclooxygenase- 2 (COX-2) [26, 27]. Furthermore, the nuclear factor- $\kappa \mathrm{B}(\mathrm{NF}-\kappa \mathrm{B})$ pathway and mitogen-activated protein kinase (MAPK) signaling pathway are also of importance and are important targets of Cynanchum paniculatum and its derivatives. The mechanism is summarized in Figure 3.

4.1. Modulation of NF- $\kappa B$ Pathway. NF- $\kappa \mathrm{B}$ represents a family of inducible transcription factors that can regulate various genes involved in immune and inflammatory responses [28]. The alteration of NF- $\kappa$ B has contributed to the pathogenesis of many inflammatory diseases, such as inflammatory bowel disease, rheumatoid arthritis, chronic obstructive pulmonary disease (COPD), and asthma [29]. Inhibition of $\mathrm{I} \kappa \mathrm{B}$ (inhibitor of NF- $\kappa \mathrm{B}$ ) phosphorylation can subsequently inhibit NF- $\kappa \mathrm{B}$ translocation, thereby preventing NF- $\kappa$ B subunits from binding to target genes and transcriptionally active inflammation. Cynanchum paniculatum had been demonstrated to dose-dependently suppresses muscle swelling by upregulating NF- $\kappa \mathrm{B}$ p 65 subunit mRNA expressions, as well as modulate its downstream genes that mediate inflammatory mediators COX-2 and interleukin-1 beta (IL-1 $\beta$ ) biosynthesis [30]. Furthermore, Cynanchum paniculatum and paeonol in pulmonary diseases, at least in part by the inhibition of Toll-like receptor 4 (TLR4)/NF- $\kappa \mathrm{B}$ inflammatory signaling [31, 32].

4.2. MAPK Signaling Pathway. In response to inflammatory stimuli, cytokines can act through Toll-like receptors and MAPK pathways leading to activation of NF- $\kappa$ B. Three major groups of distinctly regulated mitogen-activated protein kinase cascades commonly altered inhuman diseases are extracellular signal-regulated kinases (ERK1/2), mitogen-activated protein kinase p38 (p38 MAPK), and c-Jun $\mathrm{N}$-terminal kinase (JNK). Upon activation of the MAP kinases, transcription factors are phosphorylated and activated leading to a series of biological responses. In chronic bowel diseases, stroke, Alzheimer's disease, arthritis, and other chronic inflammation related diseases, MAPK pathways are frequently activated and identified as the inhibitor for drug development [33-35]. Cynanchum paniculatum and its derivatives have shown anti-inflammatory activities through suppressing lipopolysaccharides- (LPS-) induced inflammatory cytokines in macrophage as well as blocking MAPK/ ERK/p38 signaling pathway $[27,36]$.

\section{Immunomodulatory Effect of Cynanchum paniculatum}

Recent studies have indicated that the anti-inflammatory effects of Cynanchum paniculatum and its derivatives are related to the modulation of the immune system, especially regulating the macrophages activation $[10,27,36]$. Antofine and its analogues could inhibit the LPS-induced nitric oxide (NO) production in RAW 264.7 macrophage cells $[36,37]$. Antofine suppresses the expressions the inflammation related genes (such as ARG-1, IL1F9, IL-10, and IL33), the extracellular matrix related genes (such as TNC and HYAL1), and the vasopressor gene (EDN1) in LPSactivated macrophage cells [37]. Paeonol suppresses inflammatory cytokines in LPS-induced macrophage cells and protects mice from lethal endotoxin shock by regulating the production of tumor necrosis factor- $\alpha$ (TNF- $\alpha$ ), IL- $1 \beta$, interleukin-6 (IL-6), and interleukin-10 (IL-10) via inactivation of $\mathrm{I} \kappa \mathrm{B} \alpha, \mathrm{ERK} 1 / 2$, JNK, and p38 MAPK $[27,36]$. Furthermore, paeonol also reduces the nucleocytoplasmic transportation of extracellular high mobility group box 1 (HMGB1) by upregulating histone deacetylase 3 (HDAC3) $[38,39]$. It is worth noting that the anti-inflammatory and antioxidative activities of paeonol and its metabolites were found mostly through blocking MAPK/ ERK/p38 signaling pathway and PI3K/Akt/NF- $\kappa$ B pathway $[27,40,41]$. A recent study also suggests paeonol attenuates LPS-induced endothelial dysfunction and apoptosis by inhibiting bone morphogenetic protein 4 (BMP4) and TLR4 signaling independently [42]. Further study may provide further understanding to inflammatory disease and broadened the application of Cynanchum paniculatum and its derivatives.

\section{Modulation of Inflammation by Cynanchum paniculatum and Its Components in Human Diseases}

Chronic inflammation plays a major role in various chronic diseases, such as respiratory, cardiovascular, gastrointestinal, hepatobiliary, urogenital, neurological, skeletal, rheumatological systems, and cancer diseases [43-48]. The effect of Cynanchum paniculatum and its derivatives on 


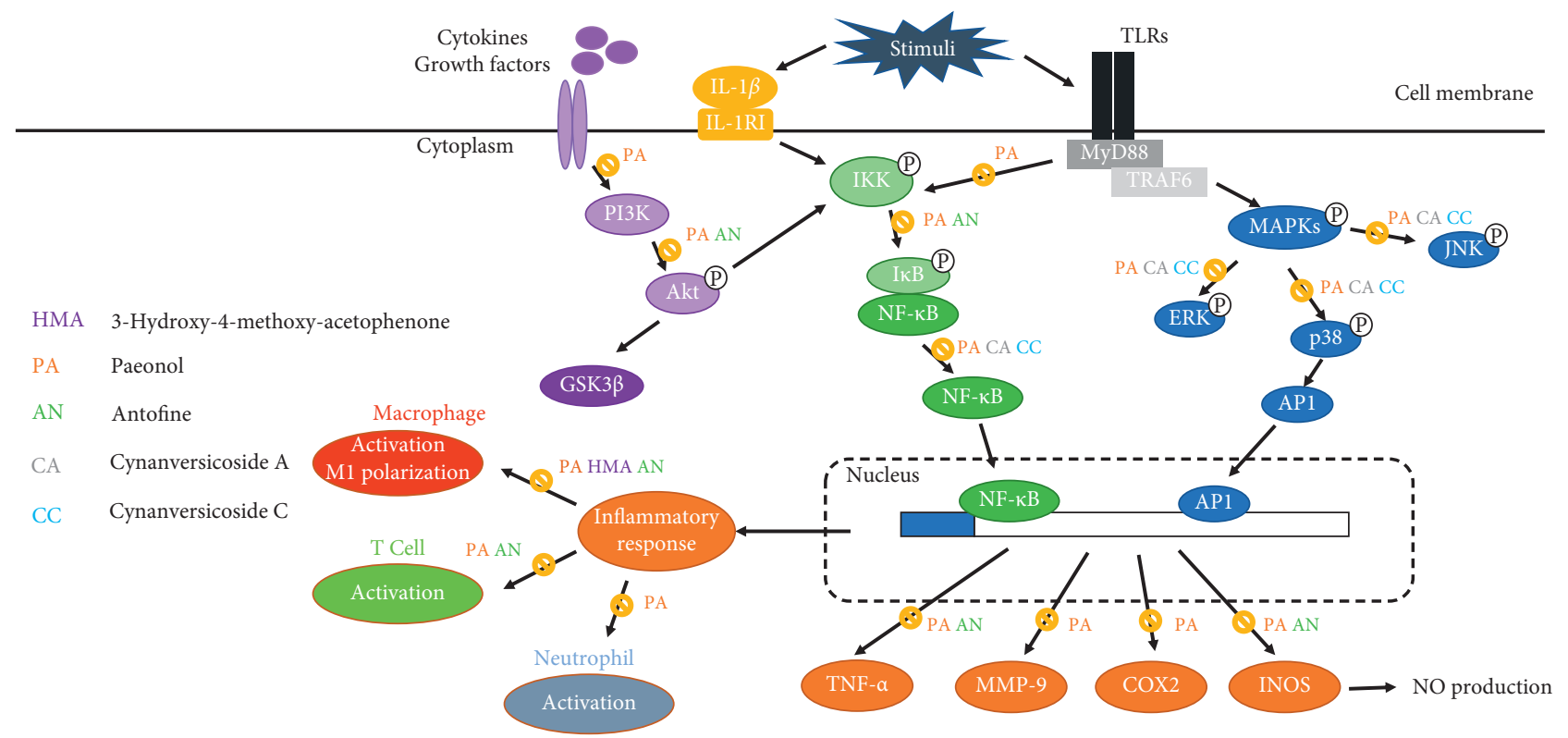

FIGURE 3: Schematic diagram of the anti-inflammatory pharmacological effects of Cynanchum paniculatum.

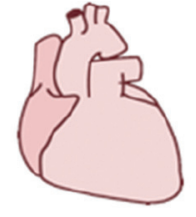

Protection against epirubcin-induced heart injury

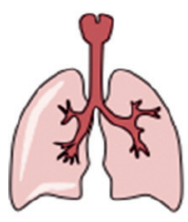

Asthma Airway inflammation Pulmonary fibrosis

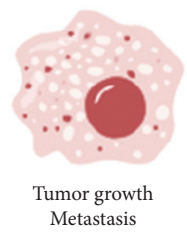

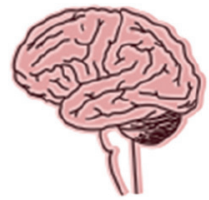

Cerebral ischemia Depression
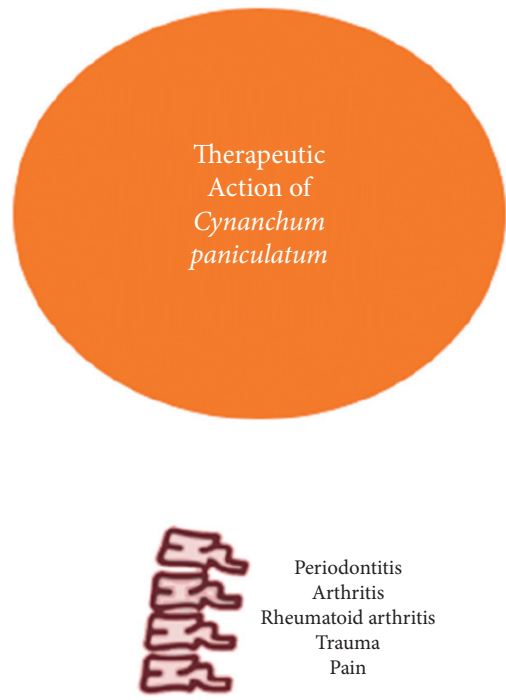

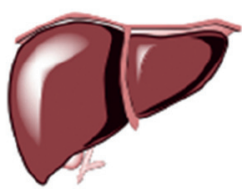

Acute alcohol-induced liver injury Hepatitis B/C infection Liver injury

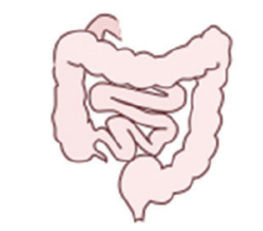

Inflammatory bowel disease Ulcerative colitis

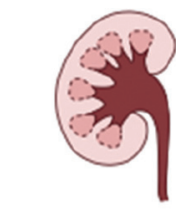

Lead-induced renal toxicity

FIGURE 4: Role of Cynanchum paniculatum chronic inflammation related human diseases.

inflammation-associated chronic human diseases are summarized by the systems, as shown in Figure 4 and Table 1.

6.1. Respiratory Diseases. As a folk medicine, Cynanchum paniculatum has a long history of application and a recognizable role for respiratory syndromes, such as cough, phlegm, and shortness of breath. Accumulating pharmacological evidence suggests the anti-inflammatory effects of Cynanchum paniculatum and its active constituents. In respiratory diseases, the inflammatory response can often be associated with an unfavourable prognosis. The elevation of inflammatory mediators, such as TNF- $\alpha$, IL- $1 \beta$, reactive oxygen species (ROS), and NO, 
TABLE 1: Pharmacological actions of Cynanchum paniculatum and its major active constituents in inflammatory-related diseases.

\begin{tabular}{|c|c|c|c|}
\hline $\begin{array}{l}\text { System of } \\
\text { diseases }\end{array}$ & Name of diseases & Related targets and pathways & References \\
\hline \multirow{4}{*}{ Respiratory } & Asthma & 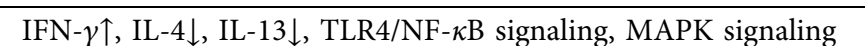 & {$[32,49]$} \\
\hline & \multirow{3}{*}{$\begin{array}{l}\text { Lung acute injury } \\
\text { Cigarette smoke-induced } \\
\text { pulmonary inflammation } \\
\text { Lung fibrosis }\end{array}$} & IL-6 $\downarrow$, MCP- $1 \downarrow$, HMGB $1 \downarrow$, NF- $\kappa$ B p $65 \downarrow$, TNF- $\alpha \downarrow$ & {$[50,52]$} \\
\hline & & MAPKs/NF- $\kappa$ B signaling, IL- $8 \downarrow$, ROS $\downarrow$ & {$[31]$} \\
\hline & & TGF- $\beta 1$-induced MAPKs/Smad3 signaling & {$[51]$} \\
\hline \multirow{4}{*}{ Cardiovascular } & $\begin{array}{l}\text { Epirubicin-induced heart } \\
\text { injury }\end{array}$ & miR-1 $\downarrow$, PI3K/Akt/mTOR pathway, NF- $\kappa$ B signaling & {$[55]$} \\
\hline & Atherosclerosis & $\begin{aligned} \mathrm{SR}-\mathrm{A} \downarrow & , \mathrm{TC} \downarrow \\
& \mathrm{TG} \downarrow, \mathrm{LCL}-\mathrm{C} \downarrow, \mathrm{MDA}-\mathrm{LDL} \downarrow \\
& \text { VCAM- CRP } \downarrow \text {, ICAM- } 1 \downarrow, \mathrm{MCP}-1 \downarrow\end{aligned}$ & {$[58-61]$} \\
\hline & Chronic gastritis & Clinical, Helicobacter pylori $\downarrow$ & {$[63]$} \\
\hline & Irritable bowel syndrome & Clinical, pain $\downarrow$ & {$[65,66]$} \\
\hline \multirow{4}{*}{ Hepatobiliary } & \multirow{3}{*}{$\begin{array}{c}\text { Chronic hepatitis B } \\
\text { Acute alcohol-induced liver } \\
\text { injury } \\
\text { Acetaminophen-induced } \\
\text { hepatotoxicity }\end{array}$} & HBsAg $\downarrow, \mathrm{HBeAg} \downarrow$ & [68] \\
\hline & & SIRT1/Nrf2/NF- $\kappa$ B signaling & {$[69]$} \\
\hline & & $\begin{array}{c}\text { Antioxidative, ALT } \downarrow \text {, AST } \downarrow \text {, p-JNK } \downarrow \text {, TNF- } \alpha \downarrow \text {, MCP- } 1 \downarrow \text {, IL- } 1 \beta \downarrow \text {, IL- } \\
6 \downarrow \text {, NF- } \kappa \text { B signaling pathway }\end{array}$ & [77] \\
\hline & Liver fibrosis & $\begin{array}{l}\text { Hepatic stellate cells } \downarrow \text {, NF- } \kappa \text { B signaling, TGF- } \beta / \text { Smad } 3 \text { signaling, } \\
\text { MMP- } 1 \downarrow \text {, MMP- } 9 \downarrow\end{array}$ & {$[74-76]$} \\
\hline \multirow[t]{2}{*}{ Urogenital } & Renal injury and renal toxicity & $\begin{array}{c}\text { ER stress } \downarrow \text {, oxidative stress } \downarrow \text {, NF- } \kappa \text { B signaling } \downarrow \text {, AMPK signaling } \downarrow \text {, } \\
\text { GSK-3 signaling pathway } \downarrow \text {, IL- } 1 \beta \downarrow \text {, TNF- } \alpha \downarrow \text {, ICAM- } 1 \downarrow \text {, VEGF } \downarrow \text {, } \\
\text { Nrf } 2 \uparrow, \text { HO- } 1 \uparrow\end{array}$ & {$[56,78]$} \\
\hline & Chronic pelvic inflammation & IL- $1 \beta \downarrow$, TNF- $\alpha \downarrow$, ICAM- $1 \downarrow$, VEGF $\downarrow$ & [56] \\
\hline \multirow[b]{2}{*}{ Neurological } & \multirow{2}{*}{$\begin{array}{l}\text { Neuronal cytotoxicity } \\
\text { Cerebral ischemia-reperfusion } \\
\text { injury }\end{array}$} & NF- $\kappa B$ signaling $\downarrow$, MAPK signaling $\downarrow$ & {$[26,80-83]$} \\
\hline & & TLR2 $\downarrow$, TLR4 $\downarrow$ & {$[84]$} \\
\hline \multirow{2}{*}{ Musculoskeletal } & $\begin{array}{l}\text { Osteoarthritis, soft tissue } \\
\text { injury, trauma }\end{array}$ & PGE2 $\downarrow$, IL- $1 \beta \downarrow, N O \downarrow, N F-\kappa B$ signaling $\downarrow$ & {$[3,6,8,30,86]$} \\
\hline & Periodontitis & Nrf2/NF- $\kappa \mathrm{B} / \mathrm{NFATc} 1$ signaling & {$[87,88]$} \\
\hline Rheumatological & Rheumatoid arthritis & 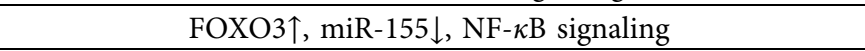 & {$[89,90]$} \\
\hline \multirow{4}{*}{ Dermatological } & $\begin{array}{l}\text { Solar ultraviolet-induced skin } \\
\text { inflammation }\end{array}$ & TOPK $\downarrow$, p-p38 $\downarrow$, JNKs $\downarrow$, MSK $1 \downarrow$, histone H2AX $\downarrow$, IL-6 $\downarrow$, TNF- $\alpha$ & {$[92]$} \\
\hline & Psoriasis & MyD88 $\downarrow$, TLR8 $\downarrow$ & [93] \\
\hline & Dermatosis & Clinical & [95] \\
\hline & Eczema & Clinical & {$[94]$} \\
\hline \multirow{9}{*}{ Malignant } & Breast cancer & CXCL4/CXCR3-B signaling, apoptosis $\uparrow$ & [103] \\
\hline & Colon cancer & RUNX $3 \uparrow$, intracellular $\mathrm{Ca}^{2+} \uparrow$, apoptosis $\uparrow$, PGE $2 \downarrow, \mathrm{COX}-2 \downarrow$ & {$[98,106]$} \\
\hline & Esophageal cancer & Bcl-2/Bax $\downarrow$, apoptosis $\uparrow$ & {$[108,109]$} \\
\hline & Gastric cancer & ERBB $2 \downarrow$, NF- $\kappa$ B signaling, MMP- $2 \downarrow$, MMP-9 $\downarrow$ & {$[97,100,102]$} \\
\hline & Liver cancer & $\mathrm{NF}-\kappa \mathrm{B}$ signaling & {$[107]$} \\
\hline & Melanoma & TNF- $\alpha$-activated NF- $\kappa$ B and IL- 6 -activated STAT3 signaling & {$[99,101]$} \\
\hline & Ovarian cancer & VEGF $\downarrow$, HIF-1 $\alpha \downarrow$, PI3K/Akt pathway & {$[105,110]$} \\
\hline & Pancreatic cancer & TGF- $\beta 1 /$ SMAD signaling & {$[112]$} \\
\hline & Prostate cancer & Apoptosis $\uparrow$, caspase- $3 \uparrow,-8 \uparrow,-9 \uparrow$, PI3K/Akt pathway & {$[111]$} \\
\hline
\end{tabular}

can be cardiodepressive and can contribute to multiorgan dysfunction syndrome with disease progression. Recently, increasing research attention and research outcomes have suggested the role of Cynanchum paniculatum and paeonol in pulmonary diseases, including asthma, airway inflammation, cigarette smokeinduced pulmonary inflammation, and fibrosis $[31,49-52]$. The mechanism of action mostly involves the inhibition of TLR $4 / \mathrm{NF}-\kappa \mathrm{B}$ and MAPK signaling and the inhibition of ROS-sensitive inflammatory signaling $[31,32]$. These research outcomes provide, at least to a certain degree, a biomedical basis for the further investigation and application of Cynanchum paniculatum in the treatment of respiratory diseases, although few related mechanisms or targets were identified.

6.2. Cardiovascular Diseases. In Shenghui Fang (Song dynasty, 992 AD), Cynanchum paniculatum was documented for the treatment of chest pain, and ever since its documentation, Cynanchum paniculatum has been widely applied for the treatment of cardiovascular diseases. In recent years, the cardiovascular pharmacological effects of Cynanchum paniculatum and its active constituents aroused widespread interest among researchers. The possible mechanism of its action might include vascular dilation 
effect by modulating ion channels $[53,54]$, promoting oxidized low-density lipoprotein (LDL) uptake by macrophage, and regulating inflammation. Previous studies suggest that the cardioprotective effect of Cynanchum paniculatum is, at least in part, due to the vascular dilation effect of paeonol by an intracellular calcium regulatory mechanism $[53,54]$. Furthermore, paeonol protects against epirubicin-induced heart injury via regulating miR-1 and PI3K/Akt pathway [55-57].

Atherosclerosis refers to the accumulation of fat, cholesterol, and other substances that led to vascular inflammation, promoting that the disease progression, when severe, can lead to coronary artery disease and heart attack. Paeonol has been shown to downregulate scavenger receptor-A (SR-A) expression, suppress uptake of oxidized LDL by macrophage, and inhibit macrophage-derived foam cell formation, which plays a crucial role in the occurrence and pathogenesis of atherosclerosis [58]. Studies have also shown that paeonol can reduce the levels of total cholesterol (TC), triglyceride (TG), and low-density lipoprotein cholesterol (LDL-C) to exert anti-atherosclerosis effects in murine models [59]. Moreover, paeonol reduces malondialdehyde-modified low-density lipoprotein (MDA-LDL) content, down-regulating NF- $\kappa \mathrm{B}$ expression. Additionally, paeonol intervention is closely related to the downregulation of other inflammation-related factors, including C-reactive protein (CRP), intercellular adhesion molecule 1(ICAM-1), vascular cell adhesion molecule 1 (VCAM-1), and monocyte chemoattractant protein-1(MCP-1) [60, 61]. Considerable documents are supporting the view that Cynanchum paniculatum can be a promising botanical remedy for cardiovascular diseases. However, current evidence is quite preliminary; the specific link between Cynanchum paniculatum and LDL scavenging still needs to be thoroughly investigated. Despite the potentially involved inflammationrelated factors which had been listed in the publications, the corresponding pathways, genes, or cytokines that might be responsible for the activation of progression of atherosclerosis are barely understood.

6.3. Gastrointestinal Diseases. The treatment of the abdominal disorder is one of the major and earliest recorded effects of Cynanchum paniculatum as folk medicine and this action may be linked to the current disease concept including ulcer, inflammatory bowel disease, liver injuries, and ascites. A previous study found that Cynanchum paniculatum and its derivatives 3-hydroxy-4-methoxy-acetophenone and paeonol possess analgesic effect and gastrointestinal motility inhibitory action [8]. Interestingly, despite the poor water solubility of paeonol, the good oral absorption rate of paeonol may, at least in part, contribute to its dose-dependent therapeutic effect on ulcerative colitis in vivo [62].

Clinically, Cynanchum paniculatum containing herbal remedies have shown certain therapeutic effects in gastrointestinal diseases, such as gastritis, ulcerative colitis, and irritable bowel syndrome (IBS). Atrophic gastritis is a process of chronic inflammation of the gastric mucosa of the stomach leading to digestive problems and may develop into gastric cancer. Yang et al. reported a Cynanchum paniculatum containing herbal remedy, the Pingwei Xiaoyi Decoction, in treating 79 cases of patients with atrophic gastritis with gastric precancerous lesions identified by gastroscopy. After treatment with the decoction for 3-6 months, $96.2 \%$ of the patients reported symptom relief, and gastroscopy and pathological examination revealed an effective rate of $79.75 \%$ [63]. It is worth noting that, among the included patients, 24 cases presented with Helicobacter pylori infection. After treatment with the decoction, the negative conversion rate of Helicobacter pylori was 58.3\%, indicating a certain therapeutic effect on Helicobacter pylori infection [63].

Moreover, the combination treatment of Cynanchum paniculatum and Radix Aucklandiae has been reported to reduce IBS-associated pain and diarrhea [64]. In a clinical observational study including 60 patients with IBS, Cynanchum paniculatum containing decoction, Li-chang-tang, relieves abdominal pain, diarrhea, and constipation in $75.9 \%, 78.4 \%$, and $78.1 \%$, respectively, after three weeks of treatment [65]. In an expert consensus published by the Chinese Society of Traditional Chinese Medicine Spleen and Stomach Disease Committee in 2009, for ulcerative colitis patients with abdominal pain, Cynanchum paniculatum is recommended to be included in treatment for pain relief [66]. Together, these studies suggest the nociceptive effects of Cynanchum paniculatum in gastrointestinal diseases. Cynanchum paniculatum might have an effect on inhibition of proinflammatory cytokine release, such as IL- $1 \beta$ and interferon-gamma (INF- $\gamma$ ), in digestive disorders. However, no experimental study is conducted to verify the role of Cynanchum paniculatum in cytokine release reaction. Furthermore, the clinical studies reported are mostly preliminary and observational and lack randomized control. Further investigations are needed to evaluate the clinical efficacy.

6.4. Hepatobiliary Diseases. The crucial roles of oxidative stress and inflammation in the development of the chronic liver disease have been emphasized for decades. Increasing evidence shows that inflammation is sustained and participated in the pathological process of chronic hepatitis, liver fibrosis, cirrhosis, and cancer. Approximately 25\% of people with chronic hepatitis B viral (HBV) infection eventually develop cirrhosis or liver cancer [67]. Traditionally recognized as a detoxifying herb, Cynanchum paniculatum water extract showed a $50 \%$ inhibitory rate against $\mathrm{HBV}$ surface antigen (HBsAg) and e-antigen (HBeAg) at a dose of $0.78 \mathrm{~g} /$ $\mathrm{L}$ and $10.13 \mathrm{~g} / \mathrm{L}$, while the $50 \%$ cytotoxic dose toward hepatic cell is $62.65 \mathrm{~g} / \mathrm{L}$ in vitro [68]. This experiment shows that Cynanchum paniculatum can effectively inhibit the secretion of two HBV antigens in vitro [68]. Other studies also suggested paeonol alleviated acute alcohol-induced liver injury via the SIRT1/Nrf2/NF- $\kappa$ B signaling pathway [69] and has antioxidation, anti-inflammation, antiapoptosis, and autophagy-induction action in vivo [70-73]. Liver fibrosis is a twound-healing response of tissue to self-repairing after injury 
and hepatic stellate cells are recognized to play a key role in the initiation, progression, and regression of liver fibrosis. Studies have shown that paeonol can inhibit the proliferation of hepatic stellate cells [74] and promote their apoptosis, and its inhibitory activity is related to the inhibition of hepatic stellate cell collagen synthesis-related protein matrix metalloproteinase 1 (matrix metallopeptidase 1, MMP-1) and MMP-9 expression [75] as well as the TGF- $\beta /$ Smad3 signaling [76]. Furthermore, paeonol attenuates oxidative stress and protects against acetaminophen-induced hepatotoxicity in vivo [77]. The low hepatotoxicity of the Cynanchum paniculatum and its protective role in liver injury allows its safe long-term use. However, clinical and laboratory studies of Cynanchum paniculatum and its derivatives in liver diseases are yet preliminary. The effects of Cynanchum paniculatum on oxidative stress and mitochondrial ROS generation, its scavenging ROS functions, and its antiapoptotic properties in chronic liver diseases are yet to be investigated. Considering the precise mechanism is still not clearly clarified, further studies focusing on the specific roles of Cynanchum paniculatum and its derivatives in chronic liver diseases should be emphasized.

6.5. Urogenital Diseases. In renal diseases, paeonol also possesses nephroprotective efficacy against lead-induced renal toxicity [78]. By suppressing endoplasmic reticulum (ER) stress in the kidney, paeonol reduces oxidative stress and decreases the NF- $\kappa \mathrm{B}$ activation and inflammatory cytokines TNF- $\alpha$ and IL- 6 overproduction via the AMPactivated protein kinase (AMPK) and glycogen synthase kinase 3 (GSK-3) pathway in vitro and in vivo [78]. Similarly, in an epirubicin-induced renal injury mice model, paeonol has a protective effect on renal function by regulating the nuclear factor erythroid 2-related factor 2 (Nrf2) and NF- $\kappa$ B pathways [56]. In a clinical study involving 30 patients with primary nephrotic syndrome treated with Cynanchum paniculatum containing remedy, the Yishen Jianpi decoction, it was reported that after 90 days of treatment, 16 out of 30 patients obtained complete relief from nephrotic syndrome. However, current studies lack investigation into precise mechanisms and clinical studies are yet observational; further studies are warranted.

In pelvic inflammatory disease (PID), Cynanchum paniculatum showed possible antimicrobial and anti-inflammatory activities as the principal component of xiaoyuningkun decoction, which also consists of Melia toosendan and Angelica biserrata. Xiaoyuningkun could significantly reduce the pain threshold in the mouse model of PID as well as the degree of inflammation in the uterus and Fallopian tubes compared with Cynanchum paniculatum decoction [79]. Cynanchum paniculatum decoction significantly reduced the serum levels of various inflammatory cytokines and adhesion molecules, including IL- $1 \beta$, TNF- $\alpha$, ICAM- 1 , and vascular endothelial growth factor (VEGF), and the expression of ICAM-1 and VEGF, in the mouse uterus and fallopian tubes [79]. These results suggest that Cynanchum paniculatum containing decoction had analgesic and anti-inflammatory effects and required further study.
6.6. Neurological Diseases. Neuroprotective effect of Cynanchum paniculatum may be linked to its traditional documentation of its invigorate blood, alleviate edema, and dredge collaterals effect. Cynanchum paniculatum methanol extract can protect mice hippocampal HT22 cells against glutamate-induced neuronal cytotoxicity [80, 81]. Consistently reported across various studies, paeonol can modulate NF- $\kappa \mathrm{B}$ signaling pathways, regulate MAPK signaling pathways, attenuate microglia-mediated inflammation, and oxidative stress-induced neurotoxicity both in vivo and in vitro $[26,82,83]$. Moreover, paeonol can suppress Toll-like receptor 2 (TLR2) and TLR4 signaling pathways and reduce proinflammatory factors in a cerebral ischemia-reperfusion injured rat model [84]. Furthermore, paeonol attenuates LPS-induced depressive-like behavior in vivo [85]. However, the exact action mechanisms are not yet fully elucidated.

6.7. Musculoskeletal Diseases. There is a long history of use of Cynanchum paniculatum in lower back pain, joint pain, and trauma. In fact, ancient Chinese documentation in the book of simplified herbs (Jianyicaoyao, in Chinese, Qing Dynasty) specifically stated the major action of Cynanchum paniculatum is for the treatment of trauma and joint pain. Contemporary studies found that paeonol alleviates IL- $1 \beta$-induced osteoarthritis in vivo and alleviates pain and inflammation in murine complete Freund's adjuvant-induced arthritis model [86]. Furthermore, the antinociceptive effect of Cynanchum paniculatum has long been regarded to be related to its anti-inflammatory effect $[3,6,8]$. A previous study identified an antinociceptive effect of the ethyl acetate fraction of Cynanchum paniculatum via oral administrations in the inflammatory pain model in vivo [3]. In daily CM practices, the combined formula in the form of water decoction is commonly used in aims to enhance therapeutic efficacy; however, the fractions of the bombinated herbal mixture of Cynanchum paniculatum were not yet studied in detail [3]. A study investigated the various fractions of an anodyne spray (XQAS) containing ethanol extracts of two herbs, Cynanchum paniculatum and Illicium henryi with topical administration for acute soft tissue injury in vivo [30]. The results showed both short-term and long-term analgesic effects of XQAS [30]. Upon administration, XQAS rapidly suppresses inflammatory mediators such as prostaglandin-E2 (PGE2), IL-1 $\beta$, and NO [30]. Further, XQAS long-term dose-dependently suppresses muscle swelling by upregulating NF- $\kappa \mathrm{B}$ p 65 mRNA expressions, as well as modulating its downstream genes that mediate inflammatory mediators COX-2 and IL- $1 \beta$ biosynthesis [30].

Cynanchum paniculatum has long been recorded for the treatment of tooth pain in Chinese literature and several clinical observations have demonstrated its potential efficacy [87]. Mechanism wise, in a ligation-induced periodontitis rat model, paeonol attenuates by inhibiting osteoclastogenesis via regulating $\mathrm{Nrf} 2 / \mathrm{NF}-\kappa \mathrm{B} / \mathrm{NFATc1}$ signaling pathway [88], while, in vivo, intraperitoneal injection of paeonol reduced the induced osteoclast formation and possessed a consistent antidestructive effect in rat experimental periodontitis models [87, 88]. These results suggested a potential antiinflammatory effect of paeonol on gingival tissue and the 
preventive role in alveolar bone loss during the process of periodontitis [87, 88]. These studies provided a scientific basis that proinflammatory cytokines inhibition may, at least in part, contribute to the treatment effect of Cynanchum paniculatum as folk medicine for periodontitis. Despite different models involved in these experiments, the role of Cynanchum paniculatum in arthritis and periodontitis requires further exploration. Besides, there are no clear and standard therapeutic dosages of Cynanchum paniculatum in studying the nociceptive effect of Cynanchum paniculatum across disease models.

\subsection{Rheumatological and Dermatological Diseases}

6.8.1. Rheumatological Diseases. In rheumatoid arthritis, paeonol possesses protective effects on inflammatory response in IL- $1 \beta$-induced human fibroblast-like synoviocytes during disease progression via modulating the NF- $\kappa \mathrm{B}$ pathway $[89,90]$. Furthermore, paeonol, by upregulating forkhead box O3 (FOXO3) through inhibition of miR-155 expression, protects against TNF- $\alpha$-induced proliferation and cytokine release of rheumatoid arthritis fibroblast-like synoviocytes $[89,90]$. Cynanchum paniculatum containing herbal capsule, the compound Fengshiding capsule (CFC), which also contains Alangium platanifolium, Angelicae dahurica, and Glycyrrhiza uralensis has been widely used as a clinical therapy against rheumatoid arthritis. Adopting the network pharmacology scheme, the potential pharmacological targets of CFC components in rheumatoid arthritis were investigated by Duan et al. [91]. It was found that CFC alters metabolic and immune-related pathways and possesses apoptotic, oxidative stress modulatory and anti-inflammatory effects that cumulatively serve for its clinical application against rheumatoid arthritis. These results supported the protective effect of Cynanchum paniculatum and its derivative on rheumatological disease progression and the mechanism might be related to inhibiting overexpressed levels of inflammatory cytokines. However, direct pathways involved in regulating hepcidin need to be investigated in the future.

6.8.2. Dermatological Diseases. Various clinical observations have reported the treatment effect of Cynanchum paniculatum in dermatological diseases. In vivo and in vitro studies suggested a protective role of paeonol against solar ultraviolet- (SUV-) induced skin inflammation via targeting T-LAK cell-originated protein kinase (TOPK), an upstream of p38 kinases and JNKs [92]. Furthermore, paeonol inhibits IL- 6 and TNF- $\alpha$ secretion in a skin inflammation mouse model [93]. Paeonol ameliorates imiquimod-induced psoriasis-like skin lesions by inhibiting the maturation and activation of dendritic cells in vivo [93]. Other clinical observational studies suggest that Cynanchum paniculatum possesses antipruritic effects in recurrent urticaria, tinea dermatosis, or pityriasis when used in decoction or external application as washing liquid [94, 95]. It is also worth highlighting that Cynanchum paniculatum containing topical ointment can alleviate skin vasculitis and is a cost-effective treatment option [96].
6.9. Malignant Diseases. The relationship between inflammation and cancer has become a hot topic for cancer research in recent years. During the process of inflammation, cytokine and growth factors are produced and subsequently activate downstream cancer-related gene and transcription factors, including NF- $\kappa \mathrm{B}$ [97-99]. Although there is an absence of the concept of cancer in ancient CM, some CM syndromes, such as damp-wind or toxicity (also known as Feng, Shi, Du in Chinese), can be easily linked to the modern concept of infection or inflammation. In view of CM, the potential anticancer effect of Cynanchum paniculatum can be ascribed to one of the CM traits by clearing wind-damp or removing toxicity. Despite the lack of direct claims to the anticancer properties of Cynanchum paniculatum, the link between anticancer and anti-inflammation can be established after anti-inflammation, anticachectic, antioxidant, antiproliferation, and antiinvasion properties [99-103].

Cynanchum paniculatum and/or its formulae have shown anticancer potential discovered in vitro and in vivo $[9,21,55,104]$. Several studies have identified that Cynanchum paniculatum and its major components could interfere with inflammatory signaling and thereby suppresses tumor development, growth, progression, and metastasis. For example, paeonol and antofine extracted from Cynanchum paniculatum have an inhibitory effect on tumor cell growth $[21,100,105]$ dose- and time-dependently $[21,98,100,105,106]$. In diethylnitrosamine-induced hepatocellular carcinoma rat models, paeonol significantly improves immunity function, protects against oxidative injury, and improves liver function [107]. It is reported that paeonol can induce apoptosis by affecting the expression of apoptosis-related genes [108-111] and has antitumor effects in vitro and in vivo [100,103], and is selective for different cell lines.

Our research group previously identified that paeonol could inhibit epithelial-mesenchymal transition of pancreatic adenocarcinoma in vitro via suppressing the transforming growth factor beta 1 (TGF- $\beta 1$ )/SMAD signaling pathway provided some evidence for future investigation into the antimetastasis effect of Cynanchum paniculatum and its derivatives [112]. Although current literature suggests an anticancer progression and metastasis role of Cynanchum paniculatum and its derivatives, no clinical experimental study has been conducted to verify the role of Cynanchum paniculatum either use as a single agent or in decoction as complementary and alternative medicine in cancer patients. Furthermore, the potential effect and interaction of Cynanchum paniculatum with chemotherapy, immunotherapy, and target therapy need to be carefully investigated in the future concerning both the efficacy and safety of the future clinical applications.

\section{Safety and Quality Control of Cynanchum paniculatum}

The $50 \%$ lethal dose (LD50) of mice injected into the peony phenol preparation by intraperitoneal injection was $32.9 \pm 1.0 \mathrm{~g} / \mathrm{kg}$ [113]. When the rabbit is injected intravenously at $5 \mathrm{~g} / \mathrm{kg}$, convulsions can occur for 30-60 seconds. The animal is in good condition within 48 hours [113]. It is 
worth noting that according to the pharmacoencyclopedia of Chinese medicinal herbs, the quality control of Xuchangqing should contain no less than $1.3 \%$ of paeonol on high-performance liquid chromatography (HPLC) fingerprint of Radix Cynanchum paniculatum [20]. Several studies have suggested that the amount of paeonol in Cynanchum paniculatum was affected by the culture environment and extraction method $[20,114]$. The dried raw herb Xuchangqing shall also be followed by other requirements (e.g., water content should not more than $16.0 \%$ and foreign matter should not more than $6.0 \%$, etc.) according to the Chinese pharmacopoeia [20]. Alarmingly, in a large, cross section survey study of pesticide contamination among 1771 herbal medical samples from 503 major cultivation areas, Cynanchum paniculatum was investigated among them [115]. The pesticide analysis result showed that 19 pesticides were detected in which seven of them were banned while eight are overlimited. The result strongly indicated that obtaining a pesticide contamination report before introducing Cynanchum paniculatum into clinical usage is of great importance to avoid pesticiderelated risk.

Among the Cynanchum genus, there are some important medicinal species in China, such as Cynanchum paniculatum and Cynanchum atratum $[13,114]$. The medicinal species in Cynanchum are easily confused, leading to potential safety risks. Through the development of identification technology, researchers identified Cynanchi Atrati Radix et Rhizoma (Baiwei in Chinese) showed a potential safety problem by discriminating 64 commercial samples of the medicinal plants [116]. By employing the internal transcribed spacer 2 (ITS2) barcode, researchers surveyed the authentication and greatly improved the identification efficiency and accuracy of commercial herbal medicines in the Cynanchum genus $[13,114,116]$. In 2006, Deng et al. reported quick and easy identification of paeonol content by the microwave-assisted extraction and headspace single-drop microextraction (MAE-HS-SDME) method for quality monitoring for the two herbal medications of Cynanchum paniculatum and Paeonia suffruticosa [13, 114, 117]. The further development of quantitative and qualitative determination of major chemical composition is warranted to improve the quality control of Cynanchum paniculatum for providing safer pharmacological applications.

\section{Discussion}

In recent years, significant achievements have been made on the identification of active components of Cynanchum paniculatum and the related action of targets in infectious diseases and chronic inflammatory diseases. In this review, the anti-inflammatory effect of Cynanchum paniculatum is linked with its ancient traditional application. Mechanism studies revealed that interference with $\mathrm{NK}-\kappa \mathrm{B}$ and MAPK pathways are major contributors to the immunomodulation effect, the anti-inflammatory effect, and the antioxidant effects of Cynanchum paniculatum and its bioactive components.
Through the literature review, most studies involved the canonical NF- $\kappa$ B pathway. The noncanonical NF- $\kappa$ B pathway in response to stimuli including the TNF receptor superfamily (TNFRSF), such as B cell-activating factor receptor (BAFF-R), cluster of differentiation 40 (CD40), and receptor activator of nuclear factor kappa-B ligand (RANKL), are worthy of further investigation to clarify the role of Cynanchum paniculatum in NF- $\kappa \mathrm{B}$-inducing kinase, p100 phosphorylation, and nuclear translocation of noncanonical NF- $\kappa$ B complex p52/RelB. In addition, the NF- $\kappa \mathrm{B}$ pathway can regulate the activation, differentiation, and effector function of inflammatory T cells. Furthermore, NF$\kappa \mathrm{B}$ is a central mediatory or NLRP3 inflammasome activation and pro-IL- $1 \beta$ response and may serve as an autoregulatory mechanism to regulate proinflammatory function. Further investigation into the related pathways may be promising for further understanding of the action mechanism of the anti-inflammatory effects of Cynanchum paniculatum and aids in the elucidation and understanding of chronic inflammatory diseases.

Recently, increasing attention has been drawn on the energy metabolic homeostasis and chronic inflammation. Metabolic syndrome, for example, had been associated with a low-grade, chronic inflammation resulting from chronic stress from nutritional overload. Paeonol has been suggested as anti-inflammatory via the AMPK pathway, where emerging results indicated AMPK signaling could inhibit the inflammatory response by NF- $\kappa$ B pathways. Instead of directly phosphorylated NF- $\kappa$ B subunits, AMPK signaling can modulate several downstream targets, such as SIRT1, PGC-1 $\alpha$, p53, and FoxO factors that subsequently inhibit NF- $\kappa \mathrm{B}$ signaling. This aspect is also worthy of further investigation. Together, the promising anti-inflammatory roles of Cynanchum paniculatum provide scientific support for future clinical application, and other identified compounds isolated from Cynanchum paniculatum may be promising, such as antofine, cynanversicoside $\mathrm{A}$, and cynanversicoside $\mathrm{C}$ and requires further study. Moreover, further investigation into a new mode of herbal medicine based on the "composition structure theory" [118] according to different functional units and chemical constituents may provide novel insights and broaden the future application of Cynanchum paniculatum. Furthermore, in in depth study into the pharmacological mechanism, pharmacokinetic and pharmacodynamics are warranted for better understanding of the role of Cynanchum paniculatum in inflammatory-related diseases.

Our research group has been studying the pathogenesis of atherosclerosis and its treatment with herbal medication [119]. Modern biomedical studies suggest that atherosclerosis is an intravascular chronic inflammation. Our preliminary clinical observation identified that herbal medication with replenishing $Q i$ and activating blood circulation effects under CM theory possess anti-inflammatory and hypolipidemic effects by reducing arterial vessel wall thickening in patients with femoral atherosclerosis. In the past 20 years, a Xuchangqing containing CM decoction " $\mathrm{Xu}$ Huang Mixture," which contains Astragali Radix (Huangqi), Typhae Pollen (Puhuang), and Epimedium brevicornum Maxim (Xianlingpi) is long used for the treatment of coronary heart disease in our group. Our preliminary clinical 
observational study showed an improvement of cardiac function and reversal or arterial plaque in patients with coronary atherosclerotic diseases when treated with $\mathrm{Xu}$ Huang mixture and standard care. We further investigated the role of Xu-Huang mixture in patients with diabetic lower extremity atherosclerotic occlusive disease. Our results showed a significant improvement of anterior tibial artery intima-media thickness (IMT), posterior tibial artery IMT, dorsalis pedis artery IMT, blood viscosity, fibrinogen, plasma D-dimer, total cholesterol, low-density lipoprotein cholesterol, and high-density lipoprotein cholesterol $(P<0.05)$. Furthermore, $\mathrm{Xu}$-Huang mixture is safe without obvious hepatic or renal toxicities. CM herbs have been characterized as multi-ingredient, multitarget therapies with low adverse effects, making them advantageous in treating certain chronic diseases. A herbal decoction is a complex mixture of different, but often closely related, herbs and compounds. The form of decoction is relatively low in toxicity due to the generally low concentration of each of the constituents, and the synergism between different constituents makes herbal decoction an interesting "cocktail" of the natural origin that can act on different targets. Further randomized double-blind clinical trials of Xu-Huang mixture for diabetic lower extremity atherosclerotic occlusive disease are needed and its expanded application to other vascular inflammatory lesions is worthy of further instigations.

\section{Conclusion}

All in all, most of the studies regarding the anti-inflammatory property of Cynanchum paniculatum and its major active constituents were recently conducted and identified in the past ten years. Despite the long history of clinical application of Cynanchum paniculatum in CM practice, many more details of its clinical potential, such as the role in inflammatory vascular diseases, future use as anticancer molecular targets, its indication on different individuals, and its pharmacodynamics and pharmacokinetics remain uncovered. Prospectively, there is a need for in vivo studies to ascertain the effect of Cynanchum paniculatum extract and its major active constituents via various application routes, such as topical, oral administration, or in the form of injections. The prospective uses of Cynanchum paniculatum in the treatment of inflammatory diseases can be derived from both traditional knowledge and modern basic research. Future the application of genomics and proteomics approaches, as well as computer-aided molecular design, may unveil novel therapeutic targets and facilitate the understanding of inflammatory diseases. In conclusion, the antiinflammation role of Cynanchum paniculatum and its bioactive components are of the therapeutic potential and worth further studies.

\section{Abbreviations}

CM: $\quad$ Chinese medicine

AMED: $\quad$ Allied and Complementary Medicine Database
CINAHL: Cumulative Index to Nursing and Allied Health Literature

CNKI: China National Knowledge Infrastructure

TNF- $\alpha$ : Tumor necrosis factor-alpha

ILs: Interleukins

COX-2: Cyclooxygenase-2

NF- $\kappa$ B: $\quad$ Nuclear factor- $\kappa$ B

MAPK: $\quad$ Mitogen-activated protein kinase

COPD: $\quad$ Chronic obstructive pulmonary disease

IL-1 $\beta$ : Interleukin-1 beta

TLR4: $\quad$ Toll-like receptor 4

ERK1/2: $\quad$ Extracellular signal-regulated kinases

JNK: $\quad$ c-Jun N-terminal kinase

LPS: $\quad$ Lipopolysaccharide

IL-6: $\quad$ Interleukin-6

IL-10: $\quad$ Interleukin-10

NO: $\quad$ Nitric oxide

ARG-1: $\quad$ Arginase 1

IL1F9: $\quad$ Interleukin-1 family member 9

IL-33: Interleukin-33

TNC: $\quad$ Tenascin C

HYAL1: $\quad$ Hyaluronoglucosaminidase 1

EDN1: $\quad$ Endothelin 1

HMGB1: $\quad$ High mobility group box 1

HDAC3: $\quad$ Histone deacetylase 3

PI3K: $\quad$ Phosphoinositide 3-kinases

Akt: $\quad$ Protein kinase B

BMP4: $\quad$ Bone morphogenetic protein 4

ROS: $\quad$ Reactive oxygen species

LDL: Low-density lipoprotein

SR-A: $\quad$ Scavenger receptor-A

TC: $\quad$ Cholesterol

TG: $\quad$ Triglyceride

LDL-C: Low-density lipoprotein cholesterol

MDA-LDL: Malondialdehyde-modified low-density lipoprotein

CRP: $\quad$ C-reactive protein

ICAM-1: Intercellular adhesion molecule 1

VCAM-1: $\quad$ Vascular cell adhesion molecule 1

MCP-1: $\quad$ Monocyte chemoattractant protein-1

IBS: $\quad$ Irritable bowel syndrome

INF- $\gamma$ : Interferon-gamma

HBV: $\quad$ Hepatitis B virus

HBsAg: $\quad$ Hepatitis B surface antigen

HBeAg: Hepatitis B e-antigen

SIRT1: $\quad$ NAD-dependent protein deacetylase sirtuin-1

Nrf2: $\quad$ Nuclear factor erythroid 2-related factor 2

MMP-1: $\quad$ Matrix metallopeptidase 1

MMP-9: $\quad$ Matrix metallopeptidase 9

ER: $\quad$ Endoplasmic reticulum

AMPK: $\quad$ AMP-activated protein kinase

GSK-3: $\quad$ Glycogen synthase kinase 3

PID: $\quad$ Pelvic inflammatory disease

VEGF: Vascular endothelial growth factor

TLR2: $\quad$ Toll-like receptor 2

XQAS: $\quad$ Xiangqing anodyne spray

PGE2: $\quad$ Prostaglandin-E2

NFATc1: $\quad$ Nuclear factor of activated T cells 1 


\begin{tabular}{|c|c|}
\hline XO3: & Forkhead box O3 \\
\hline CFC: & Compound Fengshiding capsule \\
\hline SUV: & Solar ultraviolet \\
\hline TOPK: & T-LAK cell-originated protein kinase \\
\hline TGF- $\beta 1$ : & Transforming growth factor beta 1 \\
\hline HPLC: & High-performance liquid chromatography \\
\hline $\begin{array}{l}\text { MAE-HS- } \\
\text { SDME: }\end{array}$ & $\begin{array}{l}\text { Microwave-assisted extraction and headspace } \\
\text { single-drop microextraction }\end{array}$ \\
\hline TNFRSF: & Tumor necrosis factor receptor superfamily \\
\hline AFF-R: & B cell-activating factor receptor \\
\hline 40: & Cluster of differentiation 40 \\
\hline ANKL: & $\begin{array}{l}\text { Receptor activator of nuclear factor kappa-B } \\
\text { ligand }\end{array}$ \\
\hline LRP3: & $\begin{array}{l}\text { NOD-, LRR-, and pyrin domain-containing } \\
\text { protein } 3\end{array}$ \\
\hline $\mathrm{C}-1 \alpha:$ & $\begin{array}{l}\text { Peroxisome proliferator-activated receptor- } \\
\text { gamma coactivator } 1 \text { alpha }\end{array}$ \\
\hline & 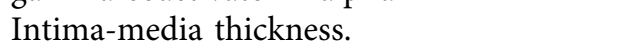 \\
\hline
\end{tabular}

\section{Disclosure}

All authors agree to be accountable for all aspects of the work.

\section{Conflicts of Interest}

The authors declare that they have no conflicts of interest.

\section{Authors' Contributions}

L.Z., C.C., and J.-X C. were responsible for conceptualization; J.-X C., C.-S C., and J.C. involved in methodology, writing, and original draft preparation,; J.-X C. and C.-S C. carried out analysis; L.-L L. and Z.-J C. were responsible for validation; J.X C., C.-S C., J.C., L.-L L., and Z.-J C. performed writing, review, and editing; C.-S C., J.C., and L.-L L. carried out visualization; L.Z. and C.C. contributed to supervision; L.Z and C.C. were responsible for funding acquisition. All authors contributed to revising the paper. Jing-xian Chen and Chienshan Cheng contributed equally to this work.

\section{Acknowledgments}

The authors would like to express their deepest gratitude to their beloved mentor Professor Xiang Xia for his consistent and illuminating instruction throughout the years. This work was supported by the Workstation of Xia Xiang, National Master of Traditional Chinese Medicine, from the State Administration of Traditional Chinese Medicine of the People's Republic of China, Shanghai Science and Technology Committee Project (Grant no. 15401932500), and the Shanghai Clinical Collaboration Construction Project of Chinese and Western Medicine (ZY(2018-2020)-FWTX-1101).

\section{References}

[1] X. S. Sun, Fengyi, Shen Nong's Herbal Classic, People's Health Press, Beijing, China, 1982.

[2] Y. X. Chen and S. P. Jiang, "Advances and application in the studies of the Pycnostelma paniculatum (Bunge) K. S. and paeonol," China Journal of Chinese Materia Medica, vol. 19, pp. 311-314, 2007.

[3] J. H. Choi, B. H. Jung, O. H. Kang et al., "The anti-inflammatory and anti-nociceptive effects of ethyl acetate fraction of cynanchi paniculati radix," Biological \& Pharmaceutical Bulletin, vol. 29, no. 5, pp. 971-975, 2006.

[4] H. Mitsuhashi, K. Hayashi, and T. Nomura, "Studies on the constituents of asclepiadaceae plants. 8. Components of Cynanchum paniculatum Kitagawa," Chemical \& Pharmaceutical Bulletin, vol. 14, no. 7, pp. 779-783, 1966.

[5] K. Sugama, K. Hayashi, H. Mitsuhashi, and K. Kaneko, "Studies on the constituents of Asclepiadaceae plants. LXVI. The structures of three new glycosides, cynapanosides A, B, and C, from the Chinese drug "xu-chang-qing," Cynanchum paniculatum Kitagawa," Chemical \& Pharmaceutical Bulletin, vol. 34, no. 11, pp. 4500-4507, 1988.

[6] J. B. Weon, B. Lee, B. R. Yun, J. Lee, and C. J. Ma, "Simultaneous determination of ten bioactive compaounds from the roots of Cynanchum paniculatum by using high performance liquid chromatography coupled-diode array detector," Pharmacognosy Magazine, vol. 8, no. 31, pp. 231-236, 2012.

[7] J. Dou, P. Li, Y. Song, L. W. Qi, and Z. M. Bi, “Application of liquid chromatography coupled with electrospray ionization time-of-flight mass spectrometry for screening and quantitative analysis of C21 steroids in the roots and rhizomes of Cynanchum paniculatum," Journal of Separation Science, vol. 30, no. 7, pp. 992-998, 2007.

[8] F. Z. Sun, M. Cai, and F. C. Lou, "Analgesic effect and gastrointestinal motility inhibitory action of 3-hydroxy-4methoxy-acetophenone from Cynanchum paniculatum (Bunge) Kitagawa," China Journal of Chinese Materia Medica, vol. 18, no. 6, pp. 362-363, 1993.

[9] S. K. Lee, K. A. Nam, and Y. H. Heo, "Cytotoxic activity and G2/M cell cycle arrest mediated by antofine, a phenanthroindolizidine alkaloid isolated from Cynanchum paniculatum," Planta Medica, vol. 69, no. 1, pp. 21-25, 2003.

[10] P. Phuneerub, W. Limpanasithikul, C. Palanuvej, and N. Ruangrungsi, "In vitro anti-inflammatory, mutagenic and antimutagenic activities of ethanolic extract of Clerodendrum paniculatum root," Journal of Advanced Pharmaceutical Technology and Research, vol. 6, no. 2, pp. 48-52, 2015.

[11] X. F. Li, Y. J. Guo, D. M. Zhang et al., "Protective activity of the ethanol extract of Cynanchum paniculatum (BUNGE) Kitagawa on treating herpes simplex encephalitis," International Journal of Immunopathology and Pharmacology, vol. 25, no. 1, pp. 259-266, 2012.

[12] W. Kim, T. S. Oh, and Y. J. Park, "Anti-viral effect of herbal medicine Korean traditional Cynanchum paniculatum (BGE.) kitag extracts," African Journal of Traditional, Complementary and Alternative medicines, vol. 14, no. 3, pp. 194-198, 2017.

[13] S. P. Jiang and Y. X. Chen, "Advances in the research and its clinical application of Cynanchum paniculatum (BGE.) Kitag," China Journal of Chinese Materia Medica, vol. 19, no. 5, pp. 311-314, 2017.

[14] W. Ji-Hong, W. Yan-Li, L. Yu-Hua, Z. Ji-Yuan, and L. I. ZeHong, "Activity of two extracts of Cynanchum paniculatum against Ichthyophthirius multifiliis theronts and tomonts," Parasitology, vol. 144, no. 2, pp. 179-185, 2017.

[15] Y. Xiong, B. Li, D. Huang, Q. He, and X. Yu, "Anti-Deinagkistrodon acutus venom properties of ethanolic root extract from Cynanchum paniculatum (Bunge) kitag and its 
GC-MS analysis," Journal of Ethnopharmacology, vol. 225, pp. 189-197, 2018.

[16] NUOC Medicine, Great Dictionary of Chinese Medicine, Shanghai Scientific \& Technical Publishers, Shanghai, China, 2006.

[17] L. Ye, Y. Jia, K. E. Ji et al., "Traditional Chinese medicine in the prevention and treatment of cancer and cancer metastasis," Oncology Letters, vol. 10, no. 3, pp. 1240-1250, 2015.

[18] M. Bai, Y. Miao, X. Lou, and M. Miao, Characteristic Analysis of Toxic Traditional Chinese Medicine Contained in Pharmacopoeia 2015, Atlantis Press, Berlin, Germany, 2018.

[19] Z. X. Z. Cai, Y. Huang, M. Chen, and X. Xia, "Discussion on clinical application of xuchangqing with Xia Xiang," Journal of Traditional Chinese Medical Literature, vol. 34, no. 4, pp. 37-39, 2017.

[20] China Medical and Technology Press, The Pharmacopoeia of the People's Republic of China, China Medical and Technology Press, Beijing, China, 2010.

[21] C. S. Kim, J. Y. Oh, S. U. Choi, and K. R. Lee, "Chemical constituents from the roots of Cynanchum paniculatum and their cytotoxic activity," Carbohydrate Research, vol. 381, pp. 1-5, 2013.

[22] M. Fu, D. Y. Wang, X. Hu, and M. Q. Guo, "Chemical constituents from Cynanchum paniculatum," Journal of Chinese Medicinal Materials, vol. 38, no. 1, pp. 97-100, 2015.

[23] S. C. Wang, X. F. Bao, and J. N. Fang, "Structural features of a neutral heteropolysaccharide CPB-4 from Cynanchum paniculatum," China Journal of Chinese Materia Medica, vol. 27, no. 2, pp. 128-130, 2002.

[24] H. Gao, W. Wang, W. Chu et al., "Paniculatumoside G, a new C21 steroidal glycoside from Cynanchum paniculatum," Revista Brasileira de Farmacognosia, vol. 27, no. 1, pp. 54-58, 2017.

[25] H.-L. Yu, Q. Long, W.-F. Yi et al., "Two new C21 steroidal glycosides from the roots of Cynanchum paniculatum," Natural Products and Bioprospecting, vol. 9, no. 3, pp. 209214, 2019.

[26] S. W. Himaya, B. Ryu, Z. J. Qian, and S. K. Kim, "Paeonol from Hippocampus kuda Bleeler suppressed the neuro-inflammatory responses in vitro via NF-kappaB and MAPK signaling pathways," Toxicology in Vitro, vol. 26, no. 6, pp. 878-887, 2012.

[27] X. Jin, J. Wang, Z. M. Xia et al., "Anti-inflammatory and antioxidative activities of paeonol and its metabolites through blocking MAPK/ERK/p38 signaling pathway," Inflammation, vol. 39, no. 1, pp. 434-446, 2016.

[28] M. Karin and Y. Ben-Neriah, "Phosphorylation meets ubiquitination: the control of NF-kappaB activity," Annual Review of Immunology, vol. 18, no. 1, pp. 621-663, 2000.

[29] S. Pai and R. Thomas, "Immune deficiency or hyperactivityNf-kappab illuminates autoimmunity," Journal of Autoimmunity, vol. 31, no. 3, pp. 245-251, 2008.

[30] S. Wang, W. Qu, T. Li et al., "Xiangqing anodyne spray (XQAS): a combination of ethanol extracts of Cynanchum paniculatum and Illicium henryi for treating soft-tissue injury," International Journal of Clinical and Experimental Medicine, vol. 8, no. 8, pp. 12716-12725, 2015.

[31] M. H. Liu, A. H. Lin, H. F. Lee, H. K. Ko, T. S. Lee, and Y. R. Kou, "Paeonol attenuates cigarette smoke-induced lung inflammation by inhibiting ROS-sensitive inflammatory signaling," Mediators of Inflammation, vol. 2014, Article ID 651890, 13 pages, 2014.

[32] Y. Tang, W. Huang, Q. Song, X. Zheng, R. He, and J. Liu, "Paeonol ameliorates ovalbumin-induced asthma through the inhibition of TLR4/NF-kappaB and MAPK signaling," Evidence-Based Complementary and Alternative Medicine, vol. 2018, Article ID 3063145, 8 pages, 2018.

[33] T. Hussain, S. Z. Shah, D. Zhao, S. Sreevatsan, and X. Zhou, "The role of IL-10 in Mycobacterium avium subsp. paratuberculosis infection," Cell Communication and Signaling, vol. 14 , no. 1 , p. $29,2016$.

[34] B. Dinda, M. Dinda, G. Kulsi, A. Chakraborty, and S. Dinda, "Therapeutic potentials of plant iridoids in Alzheimer's and Parkinson's diseases: a review," European Journal of Medicinal Chemistry, vol. 169, pp. 185-199, 2019.

[35] Q. Fang, C. Zhou, and K. S. Nandakumar, "Molecular and cellular pathways contributing to joint damage in rheumatoid arthritis," Mediators Inflamm, vol. 2020, Article ID 3830212, 20 pages, 2020.

[36] H. Y. Min, S. H. Song, B. Lee, S. Kim, and S. K. Lee, "Inhibition of lipopolysaccharide-induced nitric oxide production by antofine and its analogues in RAW 264.7 macrophage cells," Chemistry \& Biodiversity, vol. 7, no. 2, pp. 409-414, 2010.

[37] S. T. Chou, F. Jung, S. H. Yang, H. L. Chou, G. M. Jow, and J. C. Lin, "Antofine suppresses endotoxin-induced inflammation and metabolic disorder via AMP-activated protein kinase," Pharmacology Research \& Perspectives, vol. 54 pages, 2017.

[38] H. Lei, Q. Wen, H. Li et al., "Paeonol inhibits lipopolysaccharide-induced HMGB1 translocation from the nucleus to the cytoplasm in RAW264.7 cells," Inflammation, vol. 39, no. 3, pp. 1177-1187, 2016.

[39] Q. Xu, X. Liu, L. Mei et al., "Paeonol reduces the nucleocytoplasmic transportation of HMGB1 by upregulating HDAC3 in LPS-induced RAW264.7 cells," Inflammation, vol. 41, no. 4, pp. 1536-1545, 2018.

[40] X. Yuan, J. Chen, and M. Dai, "Paeonol promotes microRNA-126 expression to inhibit monocyte adhesion to oxLDL-injured vascular endothelial cells and block the activation of the PI3K/Akt/NF-kappaB pathway," International Journal of Molecular Medicine, vol. 38, no. 6, pp. 1871-1878, 2016.

[41] Y. Lou, C. Wang, Q. Tang et al., "Paeonol inhibits IL-1betainduced inflammation via PI3K/Akt/NF-kappaB pathways: in vivo and vitro studies," Inflammation, vol. 40, no. 5, pp. 1698-1706, 2017.

[42] K. W. Choy, Y. S. Lau, D. Murugan, P. M. Vanhoutte, and M. R. Mustafa, "Paeonol attenuates LPS-induced endothelial dysfunction and apoptosis by inhibiting BMP4 and TLR4 signaling simultaneously but independently," Journal of Pharmacology and Experimental Therapeutics, vol. 364, no. 3, pp. 420-432, 2018.

[43] A. B. Kunnumakkara, B. L. Sailo, K. Banik et al., "Chronic diseases, inflammation, and spices: how are they linked?" Journal of Translational Medicine, vol. 16, no. 1, p. 14, 2018.

[44] M. Watanabe, R. Tozzi, R. Risi et al., "Beneficial effects of the ketogenic diet on nonalcoholic fatty liver disease: a comprehensive review of the literature," Obesity Reviews, pp. 111, 2020.

[45] B. L. Rapoport, H. C. Steel, A. J. Theron, T. Smit, and R. Anderson, "Role of the neutrophil in the pathogenesis of advanced cancer and impaired responsiveness to therapy," Molecules, vol. 25, no. 7, 2020.

[46] S. S. Seyedizade, K. Afshari, S. Bayat et al., "Current status of M1 and M2 macrophages pathway as drug targets for inflammatory bowel disease," Archivum Immunologiae et Therapiae Experimentalis, vol. 68, no. 2, p. 10, 2020. 
[47] L. S. Strathearn, A. I. Stepanov, and J. Font-Burgada, "Inflammation in primary and metastatic liver tumorigenesisunder the influence of alcohol and high-fat diets," Nutrients, vol. 124 pages, 2020.

[48] I. Bahr, J. Spielmann, D. Quandt, and H. Kielstein, "Obesityassociated alterations of natural killer cells and immunosurveillance of cancer," Frontiers in Immunology, vol. 11, p. 245, 2020.

[49] Q. Du, G. Z. Feng, L. Shen, J. Cui, and J. K. Cai, "Paeonol attenuates airway inflammation and hyperresponsiveness in a murine model of ovalbumin-induced asthma," Canadian Journal of Physiology and Pharmacology, vol. 88, no. 10, pp. 1010-1016, 2010.

[50] P. K. Fu, C. Y. Yang, S. C. Huang et al., "Evaluation of LPSinduced acute lung injury attenuation in rats by aminothiazole-paeonol derivatives," Molecules, vol. 2210 pages, 2017.

[51] M. H. Liu, A. H. Lin, H. K. Ko, D. W. Perng, T. S. Lee, and Y. R. Kou, "Prevention of bleomycin-induced pulmonary inflammation and fibrosis in mice by paeonol," Frontiers in Physiology, vol. 8, p. 193, 2017.

[52] X. Liu, Q. Xu, L. Mei et al., "Paeonol attenuates acute lung injury by inhibiting HMGB1 in lipopolysaccharide-induced shock rats," International Immunopharmacology, vol. 61, pp. 169-177, 2018.

[53] Y. J. Li, J. X. Bao, J. W. Xu, F. Murad, and K. Bian, "Vascular dilation by paeonol-a mechanism study," Vascular Pharmacology, vol. 53, no. 3-4, pp. 169-176, 2010.

[54] J. Y. Zhang, L. Lei, J. Shang et al., "Local application of paeonol prevents early restenosis: a study with a rabbit vein graft model," Journal of Surgical Research, vol. 212, pp. 278-287, 2017.

[55] J. Wu, C. Sun, R. Wang et al., "Cardioprotective effect of paeonol against epirubicin-induced heart injury via regulating miR-1 and PI3K/AKT pathway," Chemico-Biological Interactions, vol. 286, pp. 17-25, 2018.

[56] J. Wu, L. Xu, C. Sun et al., "Paeonol alleviates epirubicininduced renal injury in mice by regulating Nrf2 and NFkappaB pathways," European Journal of Pharmacology, vol. 795, pp. 84-93, 2017.

[57] J. Wu, X. Xue, B. Zhang et al., "Enhanced antitumor activity and attenuated cardiotoxicity of Epirubicin combined with Paeonol against breast cancer," Tumor Biology, vol. 37, no. 9, pp. 12301-12313, 2016.

[58] D. H. L. Xu and S. W. Xu, "Effects of paeonol on the formation of RAW264.7 macrophage-derived foam cells," Lishizhen Medicine and Materia Medica Research, vol. 23, no. 6, pp. 1420-1422, 2015.

[59] Q. K. Z. Li, M. Y. Gong, Y. F. Fang, J. Y. Qu, and X. H. Zhou, "Effect of paeonol on coronary atherosclerosis in rats," Chinese Journal of Evidence-Based Cardiovascular Medicine, vol. 8, no. 9, pp. 1037-1039, 2018.

[60] X. F. H. Qian, D. Liu, L. Y. Qiang, and X. S. Shi, "Effects of paeonol on lipid metabolism and nuclear factor- $\kappa \mathrm{B}$ in atherosclerotic rats," China Pharmacist, vol. 17, no. 9, pp. 1441-1443, 2016.

[61] J. P. X. Cao, Y. Ma, X. Li, H. P. Sun, and D. M. Li, "Effect of paeonol on CRP in atherosclerotic rats," Chinese Journal of Integrative Medicine on Cardio-Cerebrovascular Disease, vol. 12, no. 8, pp. 991-992, 2012.

[62] S. Y. Zong, Y. Q. Pu, B. L. Xu, T. Zhang, and B. Wang, "Study on the physicochemical properties and anti-inflammatory effects of paeonol in rats with TNBS-induced ulcerative colitis," International Immunopharmacology, vol. 42, pp. 32-38, 2017.

[63] B. C. Yang, "Analysis of curative effect of Pingwei Xiaoyi Tang on 79 cases of gastric precancerous lesions," Shanghai Journal of Traditional Chinese Medicine, vol. 3, no. 5, pp. 12-14, 1994.

[64] J. M. Li, "Xuchangqing's clinical compatibility application experience," Shanxi Journal of Traditional Chinese Medicine, vol. 27 , no. 6 , pp. 736-737, 2018.

[65] S. H. C. Zheng, "Clinical observation on 60 cases of irritable bowel syndrome treated by lichang decoction," Journal of Practical Traditional Chinese Medicine, vol. 15, no. 9, p. 11, 1999.

[66] S. S. L. Zhang, H. Shen, K. Zheng, and B. Ye, "Consensus on TCM diagnosis and treatment of ulcerative colitis (2009)," Chinese Journal of Integrative Medicine, vol. 30, no. 5, pp. 527-532, 2010.

[67] T. J. Huang, H. Chuang, Y. C. Liang et al., "Design, synthesis, and bioevaluation of paeonol derivatives as potential antiHBV agents," European Journal of Medicinal Chemistry, vol. 90, pp. 428-435, 2015.

[68] B. L. Xie and R. F. Zhao, "In vitro study of Xuchangqing's water extract against hepatitis B virus," China Tropical Medicine, vol. 2, pp. 196-197, 2017.

[69] X. Sun, P. Wang, L. P. Yao et al., "Paeonol alleviated acute alcohol-induced liver injury via SIRT1/Nrf2/NF-kappaB signaling pathway," Environmental Toxicology and Pharmacology, vol. 60, pp. 110-117, 2018.

[70] X. Gong, Y. Yang, L. Huang et al., "Antioxidation, antiinflammation and anti-apoptosis by paeonol in LPS/d-GalNinduced acute liver failure in mice," International Immunopharmacology, vol. 46, pp. 124-132, 2017.

[71] H. B. W. Bo, X. Wang, and X. W. Gan, "Effects of paeonol on the expression of autophagy protein LC3 in liver tissue of mice with liver injury induced by scald," The Chinese Journal of Clinical Pharmacology, vol. 30, no. 12, pp. 1117-1119, 2019.

[72] G. M. D. Yan, Z. H. Xuan, and Y. Y. Li, "Protective effect of paeonol on acute liver cell injury," Chinese Traditional Patent Medicine, vol. 37, no. 4, pp. 854-858, 2015.

[73] G. M. D. Yang and Z. H. Xuan, "Therapeutic effect of paeonol on alcoholic fatty liver rats," Journal of Chinese Medicinal Materials, vol. 38, no. 3, pp. 550-555, 2015.

[74] D. Kong, F. Zhang, D. Wei et al., "Paeonol inhibits hepatic fibrogenesis via disrupting nuclear factor-kappaB pathway in activated stellate cells: in vivo and in vitro studies," Journal of Gastroenterology and Hepatology, vol. 28, no. 7, pp. 12231233, 2013.

[75] D. Kong, L. Chen, W. Huang et al., "Combined therapy with ligustrazine and paeonol mitigates hepatic fibrosis through destroying mitochondrial integrity of stellate cell," American Journal of Translational Research, vol. 12, no. 4, pp. 12551266, 2020.

[76] S. Wu, L. Liu, S. Yang et al., "Paeonol alleviates CCl4-induced liver fibrosis through suppression of hepatic stellate cells activation via inhibiting the TGF-beta/Smad3 signaling," Immunopharmacology and Immunotoxicology, vol. 41, no. 3, pp. 438-445, 2019.

[77] Y. Ding, Q. Li, Y. Xu et al., “Attenuating oxidative stress by paeonol protected against acetaminophen-induced hepatotoxicity in mice," PLoS One, vol. 11, no. 5, Article ID e0154375, 2016.

[78] C. M. Liu, H. X. Yang, J. Q. Ma et al., "Role of AMPK pathway in lead-induced endoplasmic reticulum stress in 
kidney and in paeonol-induced protection in mice," Food and Chemical Toxicology, vol. 122, pp. 87-94, 2018.

[79] B. Tang, K. Wu, Q. Meng, and F. Wang, "Comparison of the analgesic and anti-inflammatory effects of xiaoyuningkun decoction with Cynanchum paniculatum and fukeqianjin in a mouse model of pelvic inflammatory disease," Medical Science Monitor, vol. 25, pp. 9094-9102, 2019.

[80] J. B. Weon, C. Y. Kim, H. J. Yang, and C. J. Ma, "Neuroprotective compounds isolated from Cynanchum paniculatum," Archives of Pharmacal Research, vol. 35, no. 4, pp. 617-621, 2012.

[81] J. B. Weon, B. Lee, B. R. Yun, J. Lee, and C. J. Ma, "Neuroprotective effects of 4,5-dimethoxypyrocatechol isolated from Cynanchum paniculatum on HT22 cells," Pharmacognosy Magazine, vol. 10, no. 38, pp. 161-164, 2014.

[82] K. N. Nam, B. C. Woo, S. K. Moon et al., "Paeonol attenuates inflammation-mediated neurotoxicity and microglial activation," Neural Regeneration Research, vol. 8, no. 18, pp. 1637-1643, 2013.

[83] L. X. He, X. Tong, J. Zeng et al., "Paeonol suppresses neuroinflammatory responses in LPS-activated microglia cells," Inflammation, vol. 39, no. 6, pp. 1904-1917, 2016.

[84] W. Y. Liao, T. H. Tsai, T. Y. Ho, Y. W. Lin, C. Y. Cheng, and C. L. Hsieh, "Neuroprotective effect of paeonol mediates anti-inflammation via suppressing toll-like receptor 2 and toll-like receptor 4 signaling pathways in cerebral ischemiareperfusion injured rats," Evidence-Based Complementary and Alternative Medicine, vol. 2016, Article ID 3704647, 12 pages, 2016.

[85] W. Tao, H. Wang, Q. Su et al., "Paeonol attenuates lipopolysaccharide-induced depressive-like behavior in mice," Psychiatry Research, vol. 238, pp. 116-121, 2016.

[86] L. Huang, B. Zhang, Y. Yang et al., "Synthesis and antiinflammatory activity of paeonol analogues in the murine model of complete Freund's adjuvant induced arthritis," Bioorganic \& Medicinal Chemistry Letters, vol. 26, no. 21, pp. 5218-5221, 2016.

[87] C. Y. Chang, E. Fu, C. Y. Chiang, W. J. Chang, W. C. Cheng, and H. P. Tu, "Effect of paeonol on tissue destruction in experimental periodontitis of rats," The American Journal of Chinese Medicine, vol. 42, no. 2, pp. 361-374, 2014.

[88] J. Li, Y. Li, S. Pan, L. Zhang, L. He, and Y. Niu, "Paeonol attenuates ligation-induced periodontitis in rats by inhibiting osteoclastogenesis via regulating Nrf2/NF-kappaB/ NFATc1 signaling pathway," Biochimie, vol. 156, pp. 129137, 2019.

[89] N. Liu, X. Feng, W. Wang, X. Zhao, and X. Li, "Paeonol protects against TNF-alpha-induced proliferation and cytokine release of rheumatoid arthritis fibroblast-like synoviocytes by upregulating FOXO3 through inhibition of miR155 expression," Inflammation Research, vol. 66, no. 7, pp. 603-610, 2017.

[90] K. F. Zhai, H. Duan, L. Luo et al., "Protective effects of paeonol on inflammatory response in IL-1beta-induced human fibroblast-like synoviocytes and rheumatoid arthritis progression via modulating NF-kappaB pathway," Inflammopharmacology, vol. 25, no. 5, pp. 523-532, 2017.

[91] H. Duan, K. F. Zhai, G. J. Khan et al., "Revealing the synergistic mechanism of multiple components in compound fengshiding capsule for rheumatoid arthritis therapeutics by network pharmacology," Current Molecular Medicine, vol. 19, no. 4, pp. 303-314, 2019.

[92] P. Xue, Y. Wang, F. Zeng et al., "Paeonol suppresses solar ultraviolet-induced skin inflammation by targeting T-LAK cell-originated protein kinase," Oncotarget, vol. 8, no. 16, pp. 27093-27104, 2017.

[93] Y. Meng, M. Wang, X. Xie et al., "Paeonol ameliorates imiquimod-induced psoriasis-like skin lesions in BALB/c mice by inhibiting the maturation and activation of dendritic cells," International Journal of Molecular Medicine, vol. 39, no. 5, pp. 1101-1110, 2017.

[94] Z. Zhu, "Xuchangqing application examples," Zhejiang Journal of Traditional Chinese Medicine, vol. 22, no. 8, p. 375, 1987.

[95] B. He, "The use of Xuchangqing to treat dermatosis," Journal of New Chinese Medicine, vol. 33, no. 2, p. 41, 2001.

[96] X. Jiang, L. Liu, S. S. Li et al., "Preparation of paeonol transdermal delivery systems based on proniosomes-based ointment and its pharmacokinetics characters," China Journal of Chinese Materia Medica, vol. 39, no. 11, pp. 2131-2135, 2014.

[97] J. Fu, L. Yu, J. Luo, R. Huo, and B. Zhu, "Paeonol induces the apoptosis of the SGC7901 gastric cancer cell line by downregulating ERBB2 and inhibiting the NFkappaB signaling pathway," International Journal of Molecular Medicine, vol. 42, no. 3, pp. 1473-1483, 2018.

[98] M. Li, S. Y. Tan, J. Zhang, and H. X. You, "Effects of paeonol on intracellular calcium concentration and expression of RUNX3 in LoVo human colon cancer cells," Molecular Medicine Reports, vol. 7, no. 5, pp. 1425-1430, 2013.

[99] L. Zhang, L. Tao, T. Shi et al., "Paeonol inhibits B16F10 melanoma metastasis in vitro and in vivo via disrupting proinflammatory cytokines-mediated NF-kappaB and STAT3 pathways," IUBMB Life, vol. 67, no. 10, pp. 778-788, 2015.

[100] N. Li, L. L. Fan, G. P. Sun et al., "Paeonol inhibits tumor growth in gastric cancer in vitro and in vivo," World Journal of Gastroenterology, vol. 16, no. 35, pp. 4483-4490, 2010.

[101] L. H. Peng, S. Liu, S. Y. Xu et al., "Inhibitory effects of salidroside and paeonol on tyrosinase activity and melanin synthesis in mouse B16F10 melanoma cells and ultraviolet B-induced pigmentation in Guinea pig skin," Phytomedicine, vol. 20, no. 12, pp. 1082-1087, 2013.

[102] Z. K. Lyu, C. L. Li, Y. Jin et al., "Paeonol exerts potential activities to inhibit the growth, migration and invasion of human gastric cancer BGC823 cells via downregulating MMP2 and MMP9," Molecular Medicine Reports, vol. 16, no. 5, pp. 7513-7519, 2017.

[103] R. O. Saahene, J. Wang, M. L. Wang, E. Agbo, and D. Pang, "The antitumor mechanism of paeonol on CXCL4/CXCR3-B signals in breast cancer through induction of tumor cell apoptosis," Cancer Biotherapy and Radiopharmaceuticals, vol. 33, no. 6, pp. 233-240, 2018.

[104] T. S. Wu, C. R. Sun, and K. H. Lee, "Cytotoxic and anti-HIV phenanthroindolizidine alkaloids from Cryptocarya chinensis," Natural Product Communications, vol. 7, no. 6, pp. 725-727, 2012.

[105] H. M. Zhou, Q. X. Sun, and Y. Cheng, "Paeonol enhances the sensitivity of human ovarian cancer cells to radiotherapyinduced apoptosis due to downregulation of the phosphatidylinositol-3-kinase/Akt/phosphatase and tensin homolog pathway and inhibition of vascular endothelial growth factor," Experimental and Therapeutic Medicine, vol. 14, no. 4, pp. 3213-3220, 2017.

[106] M. Li, S. Y. Tan, and X. F. Wang, "Paeonol exerts an anticancer effect on human colorectal cancer cells through inhibition of PGE(2) synthesis and COX-2 expression," Oncology Reports, vol. 32, no. 6, pp. 2845-2853, 2014. 
[107] B. Chen, M. Ning, and G. Yang, "Effect of paeonol on antioxidant and immune regulatory activity in hepatocellular carcinoma rats," Molecules, vol. 17, no. 4, pp. 4672-4683, 2012.

[108] G. P. Sun, X. Wan, S. P. Xu, H. Wang, S. H. Liu, and Z. G. Wang, "Antiproliferation and apoptosis induction of paeonol in human esophageal cancer cell lines," Diseases of the Esophagus, vol. 21, no. 8, pp. 723-729, 2008.

[109] X. A. Wan, G. P. Sun, H. Wang, S. P. Xu, Z. G. Wang, and S. H. Liu, "Synergistic effect of paeonol and cisplatin on oesophageal cancer cell lines," Digestive and Liver Disease, vol. 40, no. 7, pp. 531-539, 2008.

[110] J. Yin, N. Wu, F. Zeng, C. Cheng, K. Kang, and H. Yang, "Paeonol induces apoptosis in human ovarian cancer cells," Acta Histochemica, vol. 115, no. 8, pp. 835-839, 2013.

[111] Y. Xu, J. Y. Zhu, Z. M. Lei et al., "Anti-proliferative effects of paeonol on human prostate cancer cell lines DU145 and PC3," Journal of Physiology and Biochemistry, vol. 73, no. 2, pp. 157-165, 2017.

[112] C. S. Cheng, J. X. Chen, J. Tang et al., "Paeonol inhibits pancreatic cancer cell migration and invasion through the inhibition of TGF-beta1/smad signaling and epithelialmesenchymal-transition," Cancer Management and Research, vol. 12, pp. 641-651, 2020.

[113] X. Xi, Analytical Chemistry, China Traditional Chinese Medicine Publishing House, Beijing, China, 2006.

[114] C. L. Fei Yang and Y. Wei, "Fluorimetric analysis of paeonol in Chinese herbal medicine Cynanchi Paniculati Radix by aluminum ion-sensitized fluorescence," Acta Pharmaceutica Sinica B, vol. 2, no. 3, pp. 294-299, 2012.

[115] L. Luo, L. Dong, Q. Huang et al., "Pesticides in herbal medicines, the insidious public health hazard: multi-residue pesticide analysis and risk assessments based on 1771 samples," SSRN Electronic Journal, 2020.

[116] M. Guo, L. Ren, and X. Pang, "Inspecting the true identity of herbal materials from Cynanchum using ITS2 barcode," Frontiers in Plant Science, vol. 8, p. 1945, 2017.

[117] C. Deng, N. Yao, B. Wang, and X. Zhang, "Development of microwave-assisted extraction followed by headspace singledrop microextraction for fast determination of paeonol in traditional Chinese medicines," Journal of Chromatography A, vol. 1103, no. 1, pp. 15-21, 2006.

[118] H. M. C. Yan, Z. H. Zhang, D. H. Yu, and X. B. Jia, "Discussion about research ideas of Chinese materia medica based on Chinese materia medica components and "composition structure" theory," Chinese Traditional and Herbal Drugs, vol. 46, no. 8, pp. 1103-1110, 2014.

[119] J. Y. Wang, J. X. Chen, L. L. Lv, X. L. Bian, and L. Zheng, "Efficacy of Xu-Huang mixtures for the treatment of diabetic lower extremity atherosclerotic occlusive disease," Journal of Shanghai Jiaotong University (Medical Science), vol. 38, no. 11, pp. 1333-1336, 2018. 